\title{
ONLINE EDUCATION: LEARNING OUTCOME, SUCCESS \& CHALLENGES
}

\author{
Michael A. Radin \\ Rochester Institute of Technology School of Mathematical Sciences, U.S.A. \\ Natalia Shlat \\ Pskov State University, Russian Federation
}

\begin{abstract}
This paper's intents are to render the learning outcome, success and challenges that emerge in an online teaching and learning environment in comparison to the traditional face to face classroom environment. First of all, we will examine how the students acclimate to the new online digital learning atmosphere after the traditional face to face learning environment; what challenges and barriers the students encounter in a synchronous and in an asynchronous online learning environments? Second of all, we will focus on how professors adapt to the new digital online teaching styles and examine the new essential teaching innovations that arise in order to achieve and go beyond the expected learning outcomes; how to remit to the students' challenges and retain the positive and engaging learning environment? In addition, our aims are to examine new pedagogical innovations that naturally emerge while responding to the students' travails and to smoothly navigate them to achieve the expected learning outcomes.

Furthermore, our paper's intents are to portray how an online learning environment can attain more effective learning outcomes in comparison to the traditional face to face classroom environment; how to think beyond our horizons and to enhance the learning outcomes in a digital learning atmosphere while addressing the students' challenges? Moreover, we will emphasize how the immediate graded feedback and students' feedback serve as pertinent tools in achieving the learning outcome and inspires students to learn in an online atmosphere.
\end{abstract}

Keywords: online education, learning outcomes, pedagogical innovations, acclimation, time management, students' feedback, immediate feedback, synchronous, asynchronous, flexibility.

\section{Introduction}

Online Education is the teaching and learning process that occurs outside the classroom via computers and related technology. Distance learning commenced in the middle of the $19^{\text {th }}$ century in the U.S. while the U.S. Postal Service was established. In 1873 the practice of distance learning transitioned to the development of "Society to Encourage Home Studies" in Boston, Massachusetts by Ana Eliot Ticknor. In 1911, using the Australian Postal System, the Department of Correspondence Studies at the University of Queensland in Australia was established. In 1946, the University of South Africa became the 
champion and innovator of distance learning. Distance learning continued with by use of television and the radio and then distance learning shifted to online education in the 1990's and widened its horizons parallel with the expansion of the digital era. In 1989 the University of Phoenix was the first university that opened its fully online bachelors and masters programs.

In Russia on the other hand, the practice of distance education commenced in 1917 after the Russian Revolution. This transitioned during the Soviet Union as a system of education at different levels based on the remote one on one individual consultations between a student and teacher/professor. In the 1960's, 11 associated universities were established with various such departments and programs. Students were first required to attend the introductory lectures and to get acquainted with the course material and requirements. After the introductory lecture the student continued to study independently in the distance education style by communicating one on one with the professor. At the end of the semester the student was required to return to the university for the exam session (Maslakova, 2015). This system partially resembled the current hybrid system today in the American educational system during the corona pandemic.

The distance education expanded in the Russian Federation after signing the memorandum with UNESCO. Afterwards this lead to the opening of MTI VTU which received accreditation in 2000 and continues to develop very actively. This institute offered numerous distance learning programs and issued diplomas. In 2005 distance learning expanded within the universities in the Russian Federation and in the training of personnel of large corporations such as the Russian Railways, SeverStal, and the Norilsk Nickel. In 2005, the Russian distance education programs were recognized on the international level by the International Association ADL (Advanced Distributed Learning).

The aims of our paper are to share successful practical experiences in teaching online courses in an asynchronous and synchronous environments in achieving the best learning outcomes while encountering several challenges such as technical challenges, lack of preparation, lack of motivation, lack of time management skills and self-discipline (Sundukova \& Vanykina, 2020). How do we handle these challenges to achieve our learning outcome goals? Can we exceed the expected learning outcome in an online atmosphere in contrast to the traditional face to face learning environment? What additional challenges and barriers can emerge and how do we deal with them (Saprykina \& Volokhovich, 2020)?

\section{Methodology}

Our methodology consists of thoroughly analyzing the data and feedback from 230 students who took asynchronous and synchronous online courses taught 
at the Rochester Institute of Technology and 110 students who took synchronous and synchronous online courses taught at Pskov State University during the spring, summer and fall 2020 semesters. Additional survey was conducted among 6 thousand students from 153 universities within the Russian Federation. We will compare the students' statistics and feedback in Table 1 and compare it with the national statistics of the Russian universities in Table 2. For instance, more than $\mathbf{5 0 \%}$ of the students in Russian universities appreciate online education as it offers them the flexibility to plan their schedule and study independently and more efficiently. Furthermore, students from universities in Moscow and Moscow Region do not have to spend close to 4 hours a day on commute and save money on rent in order to live close to the university. On the other hand, $\mathbf{5 8 . 1 \%}$ of the students in Russian universities blamed poor technical communication and low functionality of applications as one of the serious problems with online education. In addition, $\mathbf{7 0 \%}$ of the students in Russian universities in online education complained about the lack of face to face communication with fellow classmates and professors. The following chart summarizes the survey conducted by the RAEX rating agency with 6 thousand students from 153 Russian universities:

\section{Table 1 RAEX Survey Conducted from 153 Russian Universities} (Distance education, 2020 (2020))

\begin{tabular}{|l|l|l|l|l|}
\hline \multicolumn{5}{|c|}{ The available distance (online) learning opportunities (selection of several options) } \\
\hline & $\begin{array}{l}\text { Universities in } \\
\text { the top-20 } \\
\text { RAEX ratings }\end{array}$ & $\begin{array}{l}\text { Regional } \\
\text { Univer- } \\
\text { sities }\end{array}$ & $\begin{array}{l}\text { Universi- } \\
\text { ties in } \\
\text { Moscow }\end{array}$ & $\begin{array}{l}\text { Russian } \\
\text { Universities } \\
\text { on average }\end{array}$ \\
\hline $\begin{array}{l}\text { Individual work with teachers/professors } \\
\text { using video chats. }\end{array}$ & $23 \%$ & $25,9 \%$ & $32,2 \%$ & $27,4 \%$ \\
\hline Viewing recorded video lectures. & $36,1 \%$ & $33,5 \%$ & $67,6 \%$ & $40,4 \%$ \\
\hline $\begin{array}{l}\text { Monitoring progress in your personal } \\
\text { settings/account }\end{array}$ & $58,3 \%$ & $58,9 \%$ & $56,7 \%$ & $56,4 \%$ \\
\hline $\begin{array}{l}\text { Viewing “live” lectures in online format } \\
\text { (with the ability to ask questions). }\end{array}$ & $85 \%$ & $40,2 \%$ & $80,8 \%$ & $66,1 \%$ \\
\hline Attending online group video seminars & $87,5 \%$ & $40,3 \%$ & $82,4 \%$ & $69 \%$ \\
\hline $\begin{array}{l}\text { Performing interactive tasks (tests, } \\
\text { surveys, etc.) }\end{array}$ & $70,2 \%$ & $79,4 \%$ & $64 \%$ & $72,3 \%$ \\
\hline $\begin{array}{l}\text { Receiving assignments in your personal } \\
\text { settings/account. }\end{array}$ & $73,1 \%$ & $71,3 \%$ & $64,2 \%$ & $75,3 \%$ \\
\hline $\begin{array}{l}\text { Correspondence with teachers/professors } \\
\text { and exchange of documents. }\end{array}$ & $90,7 \%$ & $88,4 \%$ & $88,7 \%$ & $90,2 \%$ \\
\hline
\end{tabular}

The source: Distance education, 2020 (2020). Moscow: Raex Analytics LLC, Raex LLC. Retrieved from https://raex-a.ru/researches/distance_education/2020 
Students' learning styles change from generation to generation and most important of all change analogous to the technological innovations such as calculators, computers, tablets, cellular phones, internet sources, etc. Prior to the corona pandemic, in the U.S. in 2020 Larry Bernstein's study (Bernstein, 2019) discovered that $\mathbf{4 8} \%$ of students use their desktop computer in the classroom, $42 \%$ of the students use their smartphones, $33 \%$ use the interactive whiteboards and $20 \%$ use tablets. Furthermore, Larry Bernstein (Bernstein, 2019) claims that the technological impact of education escalates outside the classroom. His survey concludes that $64 \%$ of students use a smartphone to do their homework assignment, $65 \%$ of students do their homework on some digital notebook such as ipad, google pad, etc. (this is close to $\mathbf{8 5} \%$ in the U.S.). Moreover, Larry Bernstein claims that both the teachers and students rely on technology to enhance the quality of education by developing the autonomy in the learning process by selecting the technology that works best for them such as smartphone, laptops alone side with paper and pencil. These facts have perpetually guided students and professors to hands-on teaching and learning more outside the classroom and most important of all, to the online teaching and learning (Bernstein, 2019).

Next we will share about successful practices that lead to students' supportive feedback, teaching evaluations and the achievement of learning outcome. Most important of all, we will emphasize how immediate graded feedback and flexibility were the primary techniques that help achieve the learning outcome, retain a positive learning atmosphere and inspires students to learn in an online atmosphere.

\section{More Flexibility in an Online Learning Environment}

Online education and degrees offer alternatives and more flexibility to students who work full time and are raising families. The primary difference between online and traditional face to face learning is the fact that online education liberates the students from the usual trappings of on-campus degree programs that require commuting to the university, working out their schedule around their courses and being physically present on campus for their coursework. A high quality degree earned in an online environment should not fundamentally differ from a traditional on-campus degree. The only significant difference should be the way the courses are taught (Finch \& Jacobs, 2012; Nikulicheva, 2020).

According to Northeastern University's Online Learning Experience, in addition to flexibility and self-pace learning that online education offers to students there are six additional benefits to online education. Students who take online courses enhance their time management skills as students design their own schedule and pace and hence gain efficiency in being their own boss in order to succeed. Self-motivation \& Emotional Intelligence is another skill that 
students gain while studying in an online atmosphere by adapting to changing environments, handling multitasking responsibilities and setting priorities (Saprykina \& Volokhovich, 2020). Improved virtual communication and collaboration is another vital feature that renders the online education environment as the majority of communication is done online by e-mail and through use of various platforms. Students who take online courses gain broader and global perspectives by interacting with students from other countries as several foreign students participate in online courses. Critical thinking of course plays a vital role in all learning environments. Furthermore, the online learning environment enhances the students' refined critical thinking skills as students are expected to be more independent and focus on deeper details in comparison to the traditional face to face learning atmosphere. Every student taking an online course increases his/her learning curve with new technical skills by learning to apply new platforms such as MyCourses, skype, facebook, google meets, and using software such as latex, desmos, etc.

While the practice of online education is expanding rapidly especially during the corona crisis, on the contrary, online education just like any other ideology and practice has its limitations and drawbacks. First of all, time management and self-discipline are vital skills in order to succeed in an online learning atmosphere (Saprykina \& Volokhovich, 2020). Second of all, online education has very diminished and limited face to face interaction or none at all especially in asynchronous-style courses. Can every subject be taught online? For instance, we can certainly learn the traffic rules online but it is a good idea to learn to drive a car remotely without actually physically operating the vehicle? Online education strictly relies on computer technology and the internet. Is it safe to assume that all the students have the necessary computer literacy and technology knowledge and skills to succeed in an online course?

The motivations for applying technology in teaching and learning in an online environment have been present for quite some time as more students participate in conferences, participate in co-ops and internships while taking courses (Finch \& Jacobs, 2012). In order to support the students' aims and outcomes, it is pertinent to address the following questions. How do we deliver the course content in an online atmosphere with the use of related technology? How do we make the material and the course accessible to all students? What differences emerge in comparison to the traditional face to face classroom atmosphere and what necessary adjustments must be implemented in order to achieve the learning outcomes (Sherry, 1995)?

Recently during the corona virus pandemic, teaching online was not an option for professors and online learning was not an option for the students either. This was the first such unexpected change of atmosphere and acclimation for many students and to numerous professors as it occurred in the middle of the 
spring 2020 academic semester. How would students and professors transition smoothly and efficiently under such challenging circumstances (Sundukova \& Vanykina, 2020)? The first criteria that was recommended to all the faculty members from the administration was to be as flexible as possible with students. This then lead to the specifics of flexibility that go past the rigid standards with deadlines of homework assignments and projects that traditionally exist in the face to face courses. The second criteria that was recommended was the use of accessible technology to all the students, which includes hardware and software (Nikulicheva, 2020; Saprykina \& Volokhovich, 2020; Sundukova \& Vanykina, 2020).

Each professor or faculty member interprets flexibility differently. For instance, in the traditional face to face course Michael Radin allows exactly one re-submission of each homework assignment within one week after the students receive their graded assignment. On the other hand, in his online courses Michael allows several re-submissions for each assignment and allows his students to hand re-submissions of assignments by the end of the semester. This new trial certainly improved the students' homework grades and especially their test grades as they gained additional hands-on practice with the homework problems to absorb the material at a deeper level in comparison to the traditional face to face class. Second of all, in the traditional face to face class, Michael would grant his students extensions on the submissions of their homework assignments to 4-5 days after the deadline without any penalty points for late submissions; in the online environment, Michael allows his students hand in their assignments without any penalty points by the end of the semester as long as the students inform him that they cannot hand in their assignment by the posted deadline. This reduced the students' stress level and gave them opportunities to grasp the material at their own pace. Students also felt more comfortable asking questions in comparison to asking questions in the traditional face to face classroom atmosphere.

Acclimation is a serious factor for both students and the professors (Saprykina \& Volokhovich, 2020). The instant challenges that emerge are how to teach in a digital atmosphere without using the whiteboard and markers and how to grade homework assignments, projects \& tests without paper and pens? These are especially challenging tasks for novices in online teaching and learning. What can be done analogous to the traditional face to face classroom atmosphere and what new pedagogical innovations will be necessary to meet the expected learning outcome goal and prevent failure (Neuhauser, 2010)? In fact, Figure 1 below summarizes the common teaching strategies that have worked successfully in the traditional face to face courses and recently in online courses: 


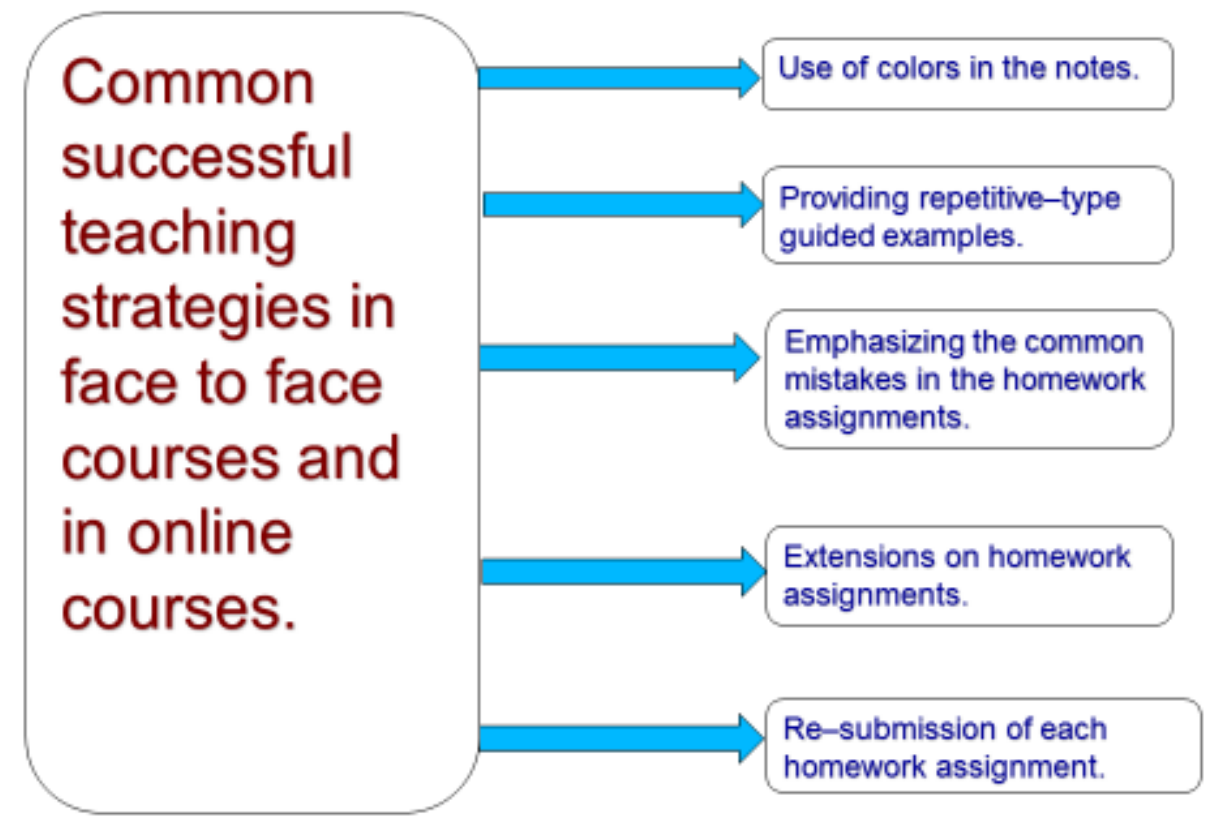

Figure 1 Teaching Strategies in Face to Face and in Online Courses

In order to address these questions more thoroughly, we will compare the similarities and differences in teaching and learning styles in the synchronousstyle online courses and in the asynchronous-style online courses.

\section{Synchronous-style vs Asynchronous-style; Similarities \& Differences}

Synchronous-style of teaching and learning involves live face to face interaction between the students and professors by the use of video systems such as skype, facebook, google meets, blue jeans and zoom. The lectures are conducted through the video system and the students can interact at any time to ask questions and suggest comments as in the regular classroom atmosphere. On the other hand, Asynchronous-style of teaching and learning has very little or no face to face interaction between students and professors and the course is conducted by the use of platforms such as MyCourses. Course lectures and videos are downloaded on a regular basis that offer students flexibility to view the notes and watch the videos on their own schedule and leisure. We will address the advantages and disadvantages of the two styles, the common goals that the two styles aim for, the common challenges that emerge in both teaching and learning styles and how to handle these nuisances smoothly and navigate the students through the challenging tasks; this directs to emotional intelligence and primal leadership (Radin \& Shlat, 2020). 
For instance, in his two hour synchronous-style classes, Michael lectures for an hour and then allows students to ask questions on their homework assignments and tests during the second hour (the second hour of class is dedicated to office hours for questions). Students can also ask the same question several times if necessary. In addition, during lecture time Michael has enough time to go over each set of notes two or more times to emphasize the vital fundamentals frequently used to solve problems, derive formulas and prove formulas. These are certainly advantages in comparison to the traditional face to face classes as there would not be enough time due to the limited available time needed to cover all the required topics. In traditional face to face courses, not all the students can attend scheduled office hours and hence have limited opportunities to ask questions on the homework assignments. In Michael's online courses students have opportunities during class time to ask questions on homework problems several times if necessary. This is also an advantage in comparison to the traditional face to face classes. Figure 2 below summarizes the new teaching strategies implemented recently in online courses:

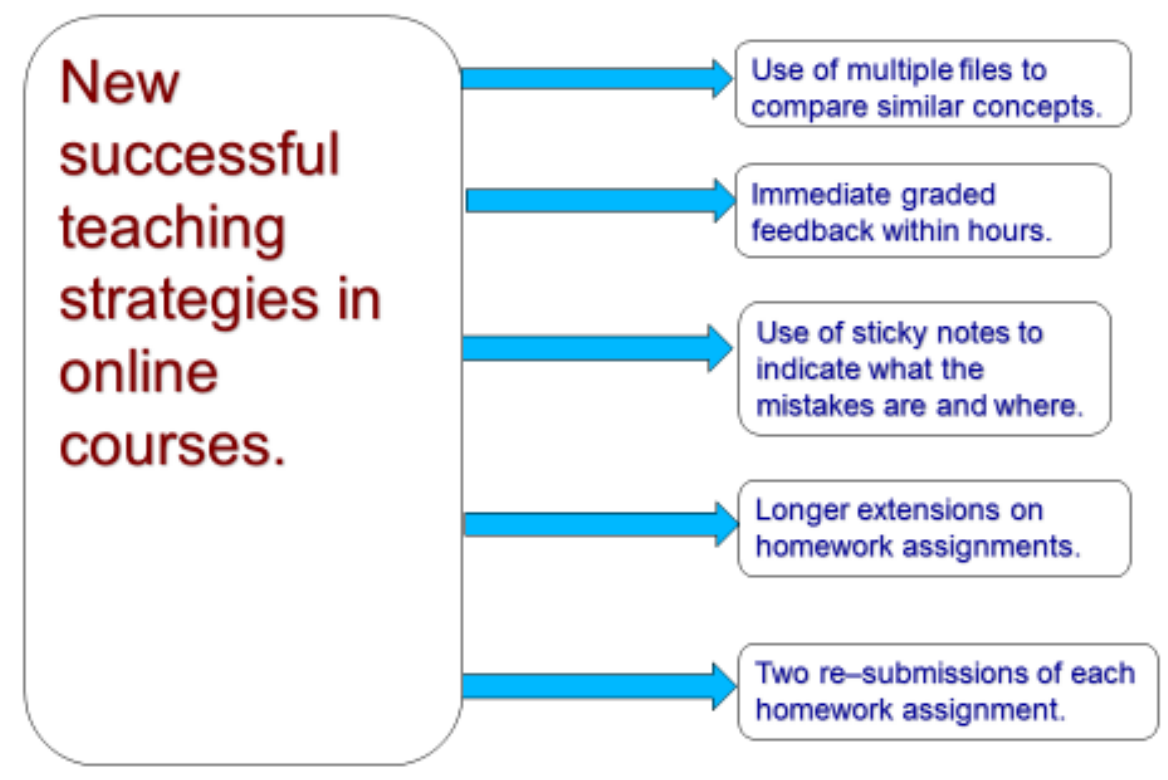

Figure 2 New Teaching Strategies in Online Courses

The next pertinent question that we will address: what are the disadvantages of the synchronous-style classes and what challenges emerge?

First of all, internet failure and technical failures with hardware can occur at any time in synchronous-style classes as they meet live. Second of all, software such as zoom, blue jeans, skype, google meets, facebook, ClickMeeting, LMS Moodle 3 (BigBlueButton) etc. can fail as well. These problems results with students missing the material and then learning and making up the material on 
their own time outside of scheduled class time (this is equivalent to missing a face to face traditional class). International students also experience serious problems with the synchronous-style classes are they can be located in various time zones world-wide and not be available to participate for various reasons such as work, family obligations, and large differences in time zones. We will mention further limitations that arise in synchronous-style courses in the later section of the paper.

On the contrary, asynchronous-style courses offer international students in different time zones more flexibility of watching the course videos and absorbing the concepts on their own schedule in comparison to synchronous-style courses. In fact, students can often watch the guided videos while traveling on public transportation and while waiting at bus stops and train stations (Nikulicheva, 2020). Problems such as internet failure and equipment failure will not cause menacing impacts such as missing the scheduled lectures. Virtual communication is essential in asynchronous-style courses as there is very little or no face to face interaction (Gallaher \& LaBrie, 2012). Virtual communication includes answering students' questions via skype, facebook, google meets and by e-mail that include the deadline of homework assignments, test dates and questions on homework assignments and on tests. It is pertinent to keep the length of the messages short and crisp as students may be in a time zone with 6-8 hours in time difference. For instance, Michael requires his students to hand in their homework assignments and tests as pdf files and then uses the sticky notes to write comments to indicate where the mistakes occur, what the mistakes are and how to correct the mistakes; students wrote frequent comments about the use of sticky notes in the course evaluations. In addition, Michael provides more repetitive-type examples in the courses' notes and guided videos as it generally takes a bit longer time for the students to grasp the material when they are attempting to learn it on their own by watching the videos without any guidance from their professor. Michael successfully used repetitive-type problems in his traditional face to face courses prior to COVID and it worked as a vital source to monitor students' common mistakes that occur throughout the learning process and emphasize them to his students (Orlova \& Radin, 2018).

Analogous to synchronous-style online courses, professors and students also experience limitations and challenges in asynchronous-style online courses (Nikulicheva, 2020). First of all, numerous students who take asynchronous-style online courses work and encounter time management problems and frequently fall behind schedule with trying to keep up with the material, with submissions of homework assignments and with their communication. Second of all, large difference in time zones can prevent students from taking scheduled quizzes, tests and exams. This becomes a challenge for professors to schedule quizzes, tests and exams; flexibility is essential in these circumstances by offering quizzes, tests and exams during different days and times. Large differences in time zones also limits 
the communication between the professors and students as it may be several hours before a professor answers the students' e-mail and vice versa and hence causes frequent delays in the communication. Swift response to questions and immediate graded feedback have been repeatedly expressed in his teaching evaluations. Table 2 below summarizes the students' comments and observations that appeared often on Michael's and Natalia's teaching evaluations:

Table 2 Frequent Comments and Observations on Students' Evaluations

\begin{tabular}{|l|l|}
\hline Immediate Graded Feedback & $92 \%$ \\
\hline Sticky Notes as written comments & $96 \%$ \\
\hline Swift Response to Questions & $95 \%$ \\
\hline Effective Response to Questions & $90 \%$ \\
\hline Flexibility with extensions on deadlines of assignments & $96 \%$ \\
\hline Flexibility of time of submission of assignments & $97 \%$ \\
\hline Resubmission of homework assignments & $94 \%$ \\
\hline Flexibility of use of technology during traveling & $96 \%$ \\
\hline Use of colors in the notes & $93 \%$ \\
\hline Effective communication in Notes & $94 \%$ \\
\hline Repetitive Guided Examples in Notes & $92 \%$ \\
\hline Length of videos 15 minutes and under & $97 \%$ \\
\hline
\end{tabular}

\section{Conclusions, Further Challenges \& Questions}

Via Tables 1 and 2, the statistics from students' feedback and course evaluations guides us to the following conclusions remitting the advantages of an online teaching and learning environment. First of all, students appreciate the immediate graded homework assignments and tests and find it an essential learning process as it accelerates the rate of understanding the concepts. This then leads to the faster speed of communication such as swift and effective responses to e-mails, swift responses to questions during synchronous lectures and the speed of exchanging information in comparison to traditional face to face courses. Second of all, students appreciate the flexibility that the online teaching and learning environment offers such as submissions and re-submissions of homework assignments, and allowing more time to ask more detailed repetitivetype questions on the material and on homework assignments which is not always possible in the traditional face to face atmosphere due to time constraints and additional limitations. Furthermore, online teaching and learning environment provides students flexibility to design their own schedule and learn at their own pace and hence go beyond the expected learning outcome as they ask more 
questions, ask more detailed questions and can solve more difficult problems. However, there are some disadvantages and challenging problems that arise with online teaching and learning atmosphere that requires further innovations and improvements.

As we mentioned previously throughout the paper, the common challenges that emerge in online teaching and learning environment include efficient time management, hard time with acclimation, internet failures, unreliable hardware and equipment, problems with software and problems with large differences in time zones. In addition, cheating and plagiarism has been a serious problem in online courses in comparison to the traditional online courses. The vital question to address is how to handle these difficulties and challenges and navigate students as smoothly as possible through the tough acclimation period and meet and exceed the learning outcome?

We will commence with the first question on developing efficient time management and acclimating to online teaching and learning. First of all offering students more flexibility with extensions on homework assignments, allowing students to re-submit each homework assignment twice, and most important of all giving students opportunities to ask questions on homework assignments during the second hour of class as many times as necessary were the essential ingredients to their acclimation to online learning. This was especially appreciated by numerous students as several students are taking many courses at the same time, working and has family obligations (a lot to do and not enough time); this is certainly an acclimation period for them.

Internet failure and unreliable equipment occurs quite frequently during online teaching and learning. One of the solutions is to keep the technology as simple as possible and apply software that is compatible with all the operating systems. Quite a few students may have outdated equipment and hence may not have access to new programs and licenses. Therefore it can be quite a substantial risk to require students to purchase a license for a program or to require them to use a specific program. This is where flexibility is again the fundamental tool that can work successfully. For instance, constructing a pdf file from hand written work can be done with older cellular phones or by inscribing photographs in a word file and then compiling the word file to a pdf file. In addition, offer students more options how to submit assignments without the purchase of licenses and we can discover various students' technological innovations. Furthermore, apply platforms that do not require high internet speed as students may not have access to high internet speed.

Even though cheating and plagiarism can be a serious problem in online courses as students have easier access to solutions and can communicate with their classmates and friends, there are still reliable methods to reduce this problem by discouraging this dishonest behavior. First, treating students honestly and 
showing that you care about your teaching is the first step to earn the students' trust and establish a positive learning atmosphere in the course. Second of all, providing prompt, accurate and honest graded feedback also strengthens the trust between the professor and the students. Last but not least swift and precise answers to students' questions and providing flexibility to students with submission of assignments increases the trust level between the professor and the students. Inspire students to learn as much as you love to teach. Just as the American actor James Drury often would say "Hope you enjoy watching the Virginian as much as I enjoy playing in the show".

\section{Acknowledgements}

In closing, we would like to take the opportunity to thank our colleagues and students at the Rochester Institute of Technology School of Mathematical Sciences, School of Life Sciences and Teaching and Learning Services and the Institute of the Education and Social Sciences at the Pskov State University for all the support, guidance and resources during this new journey of discoveries in online teaching and learning. In particular I would like to thank my department chair Mary Lynn Reed for her emphasis on offering students as much flexibility as possible once the corona pandemic began. In addition, I would like to take the opportunity to thank Sandra Connelly, Rebecca Johnson and Jeremiah Parry-Hill for their beneficial guidance in online education during novice period while teaching my first set of online courses.

\section{References}

Bernstein, L. (2019). New Global Survey Offers Snapshop of Technology in the Classroom in 2019. Classroom technology continues to evolve rapidly, but there's no replacement for pencil and paper. EdTech, Focus on K-12, February 14, 2019.

Distance education, 2020. (2020). Moscow: Raex Analytics LLC, Raex LLC. Retrieved from https://raex-a.ru/researches/distance_education/2020

Finch, D., \& Jacobs, K. (2012). Online Education: Best practices to promote learning. Proceedings of the Human Factors and Ergonomics, 56th Annual Meeting.

Gallaher, S., \& LaBrie, J. (2012). Online learning 2.0: Strategies for a mature market. Continuing Higher Education Review, 76, p. 65-73.

Maslakova, E. S. (2015). History of the development of distance learning in Russia. Text: direct // Theory and practice of education in the modern world: materils of the VIII International Scientific Conference, St. Petersburg, Russia, St. Petersburg Publishing House, p. 29-32. URL: https://moluch.ru/conf/ped/archive/185/9249/

Neuhauser, C. (2010). Learning Style and Effectiveness of Online and Face-to-Face Instruction. American Journal of Distance Education, 16(2), p. 99-113.

Nikulicheva, N. V. (2020). Methodology for developing a distance course. Actual problems of methods of teaching computer science and mathematics in a modern school: material of 
Proceedings of the International Scientific Conference. Volume I, May 28 ${ }^{\text {th }}-29^{\text {th }}$, 2021. 524-536

the International Scientific and practical Internet conference, Moscow, April 24 - May 12, 2020/ ed. L. Bosonov, D.I. Pavlova. Moscow State Pedagogical University, p. 665-695.

Orlova, O., Radin, M. (2018). University level teaching styles with high school students and international teaching and learning. Society, Integration, Education. Proceedings of the International Scientific Conference, I, p. 464-475. DOI: http://dx.doi.org/ 10.17770/sie2018vol1.3321

Radin, M., \& Shlat N. (2020). Value orientations, emotional intelligence and international pedagogical innovations. The proceedings of the 7th International Scientific Conference "Society, Integraton, Education". May 22 - 23, 2020, III, p. 732-742. DOI: http://dx.doi.org/10.17770/sie2020vol2.4858

Saprykina, D. I., \& Volokhovich, A. A. (2020). Problems of transition to distance learning in the Russian Federation through the eyes of teachers; National Research University Higher School of Economics, Institute of Education. Moscow: NRU HSE. Retrieved from https://ioe.hse.ru/data/2020/05/27/1550223489/ФО_4(29)_электронный.pdf

Sherry, L. (1995). Isues in distance learning. International Journal of Educational Telecommunications, 1(4), p. 337-365.

Sundukova, T. O., \& Vanykina, G. V. (2020). Challenges of online learning in higher education in the context of COVID-19. Socio-psychological problems of modern society and man: solutions: collection of scientific articles / comp.: E.N. Busel-Kuchinskaya, N.E. Shabanov; under scientific. Ed. E.L. Mikhailova; otv. for issue. S.A. Motors. Vitebsk: Voronezh State University named after P.M. Masherova, p. 293-296. 